\title{
Does Higher Percentages of Women With Higher Education Within District Impacts Individuals Use of Contraception in Uttar Pradesh?
}

\author{
Richa Sharma ${ }^{1}$, Ajay Pandey $^{2}$ \\ ${ }^{1}$ Deputy Director, National Institute of Labour Economics Research \& Development, Delhi, India \\ 2 Assistant Director, Population Research Centre, University of Lucknow, India \\ Correspondence: Ajay Pandey, Assistant Director, Population Research Centre, University of Lucknow, India
}

Received: June 8, 2020 Accepted: June 28, 2020 Online Published: June 29, 2020

doi:10.5539/ijsp.v9n4p78 URL: https://doi.org/10.5539/ijsp.v9n4p78

\begin{abstract}
Uttar Pradesh in India is high fertility state which contributes maximum to India's population growth. The use of family planning method is amongst the lowest in the State and has witnessed a decline during the two consecutive National Family Health Survey (NFHS) period of round $3 \& 4$. The use of any methods of contraception declined from $56.3 \%$ in 2005-06 to 53.5\% in 2015-16. A decline of 2.8 percent points in-spite of all the programmatic push. Similarly, the use of any modern contraceptive methods declined from $48.5 \%$ to $47.8 \%$ during this period. This decline in the use of contraception necessitates revisiting determinants of contraceptive use at the district (group) level. The availability of district level data from NFHS-4 makes it possible to estimate between district variations in contraceptive use in UP. The Intra-class correlation coefficient of 0.1528 reveals that 15.28 percent of the variation in contraceptive use is due to between district differences in Uttar Pradesh while 84.72 percent variation is due to within district individual differences. At individual level younger age, higher parity, Hindu religion, educated secondary or higher school levels and those belonging to higher SES other than poor quintile have significant higher odds of contraceptive use. At district (group) level, the higher percentages of women educated higher school levels within district significantly determines the use of contraception in Uttar Pradesh.
\end{abstract}

Keywords: contraception, intra-class correlation, education

\section{Introduction}

India's population increased from 238.4 million in 1901 to 1028.7 million in 2001. The 2011 Census figures returned India's population figure as 1210.2 million. If we divide the population increase during 1901-2001 into two half, it can be observed that the $16 \%$ of the total increase occurred in the first 50 years and the remaining $84 \%$ of the increase occurred during the second half of the twentieth century. The large percentage increase in the second half of the twentieth century may primarily be due to technological advancement in medical science resulting in fewer deaths. The increase in population during second half of the twentieth century took place in-spite India being the first country in 1951 to adopt official family planning program. The family planning program in India was largely sterilization centric until ICPD 1994. Sterilization was used as a means to reduce fertility and it was adopted by those who had completed their family size. The policy makers failed to capture the "too early too fast" phenomenon of the Indian fertility behavior (Srinivasan, 2001). In the year 2005 Government of India launched the National Rural Health Mission programs as a centrally funded scheme to improve health infrastructure and health outcomes in the States. Over the years the increased allocation in Family Planning was aimed at reducing fertility rates which even today is highest in Uttar Pradesh. The data from two inter-NFHS survey period including NFHS-3 (2005-6) (IIPS, 2007) and NFHS-4 (2015-16) (IIPS, 2017) saw a decline in the contraceptive prevalence rate in Uttar Pradesh. It may be safe to presume the total neglect of family planning program in Uttar Pradesh after the launch of National Rural Health Mission programs in 2005. The prevalence of any method of contraception declined from 56.3\% in 2005-06 to 53.5\% in 2015-16 in Uttar Pradesh. A decline of 2.8 percent points in-spite of all the programmatic push under the National Health Mission programs. The prevalence of any modern methods of contraception declined from $48.5 \%$ to $47.8 \%$ during the NFHS-3 \& NFHS-4. A decline of 0.7 percent points in ten years of NRHM programs in the State. The level of contraception in any given population has direct bearing on the total fertility rate. It has been mathematically proven that keeping other factors constant, the contraceptive prevalence rate of 60 percent is necessary condition for replacement level fertility rate of 2.1 children per women. It is therefore important to study determinants of contraceptive prevalence in Uttar Pradesh in order to suggest policy interventions leading to better utilization of family 
planning services in the State. NFHS-4 dataset for the first time provided information at the district (group) level. This study using Hierarchal Logit Models analyzes the determinants of contraceptive use both at Individual level and at district (group) level, by capturing the between district and within district individual variances.

NFHS-4 data on contraceptive prevalence in Uttar Pradesh indicates that inspite of promoting the method mix of family planning program the female sterilization remains the most preferred method of family planning. Male involvement in family planning has been negligible. Over the ten year period during NFHS-3 \& NFHS-4 the percentage share of male sterilization among contraceptive prevalence declined from 0.2 percent in NFHS-3 to 0.1 percent in NFHS-4. It needs to be analyzed separately to study the reasons behind low levels of male involvement in family planning program in Uttar Pradesh. One of the reasons of male alienation from family planning program may be attributed to the compulsory male sterilization policy of 1976-77. However it is matter of indepth analysis which is beyond the scope of the present paper.

\section{Objectives}

- Estimate the Intra-class correlation to study the between district differences in contraceptive use in Uttar Pradesh

To estimate the individual level (level-1) determinants of contraceptive use in Uttar Pradesh

- To study the impact of percentage of women educated higher levels within district (level-2) and its impact in determining the contraceptive use at individual level (level-1) in Uttar Pradesh

\section{Methods}

NFHS-4 data for Uttar Pradesh is used for analysis. Total 66,489 currently married women who are current users of contraception formed the basis of analysis. The district (group) level information on percentages of women educated higher levels (12+grades) was available from 71 districts of Uttar Pradesh. Multilevel modeling technique was used to study the impact of district (group) level factor on individual outcome. Multilevel modeling provides a robust method for analyzing hierarchically clustered data, while allowing measurement of the influence of group level (district) factors and unobserved group (district) effects on individual behavior (Stephenson, Beke, \& Tshibangu, 2008). The outcome variable in the study is dichotomous, indicating whether or not woman uses any modern contraceptives (sterilization, pills, condom, injectables, Intra-Uterine Device, rhythm/periodic abstinence, withdrawal, lactational amenorrhea, foam or jelly, standard days etc.). If a woman was using any of the above contraceptives she was assigned the code 1 and considered as using a modern contraceptive else code 0 which indicates she was not using any of the above modern contraceptive methods. Individual level demographic factors (level-1) used in the analysis include age, education, religion, children ever born and place of residence. Wealth index quintiles were used to represent the socioeconomic status (SES) of the household. In order to measure the group level (district) factors affecting the contraceptive use, percentage of women educated higher levels (12+grades) in the district was used as Level-2 variable.

As the outcome variable of the analysis is dichotomous, representing whether or not women was a users of family planning method at the time of survey, and the data sets being hierarchical in nature as the individual women are nested within households and the households are nested within districts, choice of multilevel modeling technique was obvious. Multilevel modeling accounts for the hierarchical structure of the data and facilitates the estimation of group (district) level influences on individual contraceptive use. The multilevel modeling strategy also corrects the estimated standard errors to allow for clustering of observations within units. Using multilevel analysis one can also control for a range of individual, household, district level factors influencing outcome (Goldstein, 1995).

From the multilevel analysis one can estimate the group level variance in contraceptive use or variance due to between district differences. These variances represent the unexplained variation in contraceptive use that remains after accounting for the factors included in the model at individual level (Stephenson, Baschieri, Clements, Hennink, \& Madise, 2007). For the study two-level hierarchical linear model is used, with individual women (level-1) nested within districts (level-2). The model is written as

$$
\operatorname{logit}\left(\mathrm{P}_{\mathrm{ij}}\right)=\mathrm{x}_{\mathrm{ij}} \mathrm{B}+\sigma_{\mathrm{uj}}
$$

where $P_{i j}$ is the probability of contraceptive use by the $i^{\text {th }}$ woman in the $j^{\text {th }}$ district. $x_{i j}$ is a vector of covariates corresponding to the $\mathrm{i}^{\text {th }}$ woman in the $\mathrm{j}^{\text {th }}$ district. $\mathrm{B}$ is a vector of unknown parameters. The distribution of random effects is assumed to be normal: with mean zero and variance $\sigma_{u}$, when $\sigma_{u}=0$ the model reduces to the ordinary logistic model, indicating there is no significant correlation in modern contraceptive use between districts (Rabe-Hesketh, Skrondal, \& Pickles, 2004; Sharma, Naresh, \& Ghimire, 2011).

\section{Findings \& Discussion}

Table 1 presents the sample characteristics of the individual and district (group) level variables used in the analysis. Off the 66,489 currently married women 52.5 percent are not using any method of contraception. The mean age of the respondents in the sample is 32.6 years. About 10.44 percent of the currently married respondents reported no-child, 
while 34.2 percent respondents have 2-children and 55.3 percent of the respondents had 3 or more children. Those illiterate in the sample are 45.7 percent, while 12.9 percent of the respondents are educated either below primary or completed-primary school level. Respondents educated either incomplete-secondary or completed-secondary level of schooling constituted 30.7 percent. Those educated more than secondary school level (12+grades) accounted for 10.6 percent.

Three fourth of the respondents are from rural areas. Eighty one percent of the sample respondents are Hindus. Respondents belonging to poorest wealth index quintile are 25.87 percent, while those who belonged to poorer quintile are 23.04 percent, 18.2 percent of the respondents belonged to middle wealth index quintile, while 16.04 percent respondents are from category richer wealth index quintile and 16.84 percent belonged to richest quintile category.

At level-2 (district/group) the average percentage of women educated higher and above is 13.2 percent, ranging from minimum of $2.1 \%$ in Shrawasti district of Uttar Pradesh to maximum of $27.35 \%$ in Kanpur Nagar district.

Table 1. Percentage distribution of 66,489 married women aged 15-49 by selected characteristics and means: NFHS-4 Uttar Pradesh

\begin{tabular}{|c|c|c|}
\hline Variables & Freq. & Percent \\
\hline \multicolumn{3}{|l|}{ Level-1 } \\
\hline \multicolumn{3}{|l|}{ Current use of contraception } \\
\hline Not using & 34,925 & 52.53 \\
\hline Using & 31,564 & 47.47 \\
\hline Current Age (mean) & 66489 & 32.58 \\
\hline \multicolumn{3}{|l|}{ Children ever born } \\
\hline 0 & 6942 & 10.44 \\
\hline upto 2 & 22754 & 34.22 \\
\hline 2 plus & 36793 & 55.34 \\
\hline \multicolumn{3}{|l|}{ Education } \\
\hline Illiterate & 30,381 & 45.69 \\
\hline Upto primary & 8606 & 12.95 \\
\hline Upto secondary & 20441 & 30.74 \\
\hline Higher & 7061 & 10.62 \\
\hline \multicolumn{3}{|l|}{ Place of Residence } \\
\hline Rural & 49,486 & 74.43 \\
\hline Urban & 17,003 & 25.57 \\
\hline \multicolumn{3}{|l|}{ Religion } \\
\hline Hindu & 54,209 & 81.53 \\
\hline Others & 12,280 & 18.47 \\
\hline \multicolumn{3}{|l|}{ Wealth Index } \\
\hline Poorest & 17,204 & 25.87 \\
\hline Poorer & 15,321 & 23.04 \\
\hline Middle & 12,100 & 18.2 \\
\hline Richer & 10,664 & 16.04 \\
\hline Richest & 11,200 & 16.84 \\
\hline \multicolumn{3}{|l|}{ Level-2 } \\
\hline Percentage of women educated $>12$ (mean) & 66489 & 13.18 \\
\hline
\end{tabular}

Table 2 presents the estimate of intra class correlation (ICC). ICC shows the between district variation in contraceptive use in Uttar Pradesh. The null model without any covariates is used to estimate the ICC. The findings indicate significant unexplained district-level (level-2) variance in modern contraceptive use $\left(\sigma_{u}^{2}=0.59\right)$. ICC value of $15.3 \%$ [ $\rho$ $=0.594 /(0.59+3.29)]$ indicates the amount of variation in modern contraceptive use that is due to between district (group) variations. Here, $\rho$ stands for the intra district correlation for the null model and is given by $\rho=\sigma_{u 0}^{2} /\left(\sigma_{u 0}^{2}+\pi^{2}\right.$ /3), where $\sigma_{u}^{2}$ is the variance at the district level and $\pi=3.14$ (Hox, 2010). The introduction of individual level factors (level-1) in the model as presented in table- 3 shows the value of intra class correlation as 0.163 which is higher from the value presented in the table-2. This indicates that after the introduction of level-1 variable in the model, the between district variance increased. 
Table 2. Intra class Correlation Hierarchical Logit Model (HLM)

\begin{tabular}{|c|c|c|c|c|c|c|}
\hline \multicolumn{7}{|c|}{ Mixed Effect Logit Model } \\
\hline \multicolumn{7}{|c|}{66498 observations nested in 71 districts (groups) } \\
\hline \multicolumn{7}{|c|}{ Observations per group } \\
\hline Min & & & & & & 567 \\
\hline Avg. & & & & & & 936.5 \\
\hline Max & & & & & & 2221 \\
\hline \multicolumn{7}{|c|}{ Integration method: mvaghermite } \\
\hline Integration points & & & & & & $=7$ \\
\hline Log-likelihood & & & & & & -42526.103 \\
\hline Contraceptive Use & Coef. & Std. Err. & $\mathrm{z}$ & $\mathrm{P}>\mathrm{Z}$ & & $\mathrm{CI}]$ \\
\hline Constant & -0.2453874 & 0.091871 & -2.67 & 0.008 & -0.425451 & -0.06532 \\
\hline \multicolumn{7}{|l|}{ District (Level2) } \\
\hline Var (Constant) & 0.5934922 & 0.101977 & & & 0.4237965 & 0.831137 \\
\hline \multicolumn{7}{|c|}{ Intra class Correlation } \\
\hline Level & ICC & Std. Err. & & & & $\mathrm{CI}]$ \\
\hline Groups (districts) & 0.1528295 & 0.022247 & & & 0.1141181 & 0.201683 \\
\hline
\end{tabular}

Table 3 presents the determinants of contraceptive use in Uttar Pradesh at individual level. The respondent's current age is a significant factor that explains the use of contraception. For one year increase in the mean age at marriage of the respondents the use of contraception in likely to increase 1.01 times. Similarly, respondents who have up-to two children have 10.5 times higher odds of using contraception compared to those who have no-child. Respondents who have three or more children have 22.3 times higher odds of using contraception than respondents who have no-child. The IEC programs should focus on respondents who have two or more children as the odds of using contraception is highest among them compared to those who either do not have any child or have two child. 
Table 3. Predictors of Contraceptive Use in Uttar Pradesh: HLM - Odds Ratio

\begin{tabular}{|c|c|c|c|c|c|c|}
\hline \multirow{2}{*}{$\begin{array}{l}\text { Independent Variable } \\
\text { Level-1 } \\
\text { Current Age } \\
\text { (mean centered) }\end{array}$} & Odds Ratio & Std. Err. & $\mathrm{Z}$ & $\mathrm{P}>\mathrm{Z}$ & \multicolumn{2}{|c|}{$[95 \% \mathrm{CI}]$} \\
\hline & 1.01 & 0.00 & 9.64 & 0.00 & 1.01 & 1.02 \\
\hline $\begin{array}{l}\text { Children ever born } \\
0 \text { (Ref.) } \\
\text { upto } 2 \\
2 \text { plus }\end{array}$ & $\begin{array}{c}1.00 \\
10.46 \\
22.26\end{array}$ & $\begin{array}{l}0.52 \\
1.17\end{array}$ & $\begin{array}{l}47.33 \\
58.93\end{array}$ & $\begin{array}{l}0.00 \\
0.00\end{array}$ & $\begin{array}{c}9.49 \\
20.08\end{array}$ & $\begin{array}{l}11.53 \\
24.68\end{array}$ \\
\hline $\begin{array}{l}\text { Education } \\
\quad \text { Illiterate (Ref.) } \\
\text { Upto primary } \\
\text { Upto secondary } \\
\text { Higher }\end{array}$ & $\begin{array}{l}1.00 \\
1.08 \\
1.19 \\
1.39\end{array}$ & $\begin{array}{l}0.03 \\
0.03 \\
0.05\end{array}$ & $\begin{array}{l}2.75 \\
7.35 \\
8.64\end{array}$ & $\begin{array}{l}0.01 \\
0.00 \\
0.00\end{array}$ & $\begin{array}{l}1.02 \\
1.14 \\
1.29\end{array}$ & $\begin{array}{l}1.14 \\
1.26 \\
1.49\end{array}$ \\
\hline $\begin{array}{l}\text { Place of Residence } \\
\text { Rural } \\
\text { Urban }\end{array}$ & $\begin{array}{l}1.00 \\
1.09\end{array}$ & 0.03 & 3.24 & 0.00 & 1.03 & 1.14 \\
\hline $\begin{array}{l}\text { Religion } \\
\text { Hindu } \\
\text { Others }\end{array}$ & $\begin{array}{l}1.00 \\
0.53\end{array}$ & 0.01 & -24.61 & 0.00 & 0.50 & 0.56 \\
\hline $\begin{array}{l}\text { Wealth Index } \\
\text { Poorest (Ref.) } \\
\text { Poorer } \\
\text { Middle } \\
\text { Richer } \\
\text { Richest }\end{array}$ & $\begin{array}{l}1.00 \\
1.14 \\
1.28 \\
1.39 \\
1.53\end{array}$ & $\begin{array}{l}0.03 \\
0.04 \\
0.05 \\
0.06\end{array}$ & $\begin{array}{c}4.87 \\
8.50 \\
10.16 \\
11.12\end{array}$ & $\begin{array}{l}0.00 \\
0.00 \\
0.00 \\
0.00\end{array}$ & $\begin{array}{l}1.08 \\
1.21 \\
1.31 \\
1.42\end{array}$ & $\begin{array}{l}1.19 \\
1.36 \\
1.49 \\
1.65\end{array}$ \\
\hline $\begin{array}{l}\text { Constant } \\
\text { Level-2 } \\
\text { Groups (district) } \\
\quad \text { Var. (constant) }\end{array}$ & 0.05 & 0.01 & -28.10 & 0.00 & 0.04 & 0.06 \\
\hline
\end{tabular}

Compared to illiterate respondents those educated either upto incomplete primary or completed primary school levels have 1.08 times odds of using contraception. Similarly respondent's educated up-to secondary school level have 1.19 times odds of using contraceptive compared to illiterates. Respondents having educated above secondary school levels are 1.39 time more likely to use contraception compared to illiterate women. The findings reinforce the importance of female education as it increases the odds of using contraception. The educated women are capable of making informed decisions about their reproductive goals and thus can effectively space/limit births using effective method of contraception. Urban respondents are 1.09 time more likely to use contraception than rural counterparts. Respondents belonging to other religious groups are less likely to use contractive compared to Hindus. Hindus are twice more likely to use contraception compared to other religious group respondents. Respondents belonging to poorest category wealth index quintile are 1.14 times more likely to use contraception compared to poorer respondents. Respondents who belonged to middle wealth index quintile are 1.28 times more likely to use the contraception compared to poorer category respondents. Respondents belonging to richer wealth index quintile are 1.39 time more likely to use contraception compared to poorer counterparts. Similarly, respondents from richest quintile are 1.53 times more likely to use contraception compared to poorer wealth quintile respondents. The likelihood ratio test comparing the models, with ordinary logistic regression, shows random effect model being more significant. 
Table 4 below provides the odd ratio estimates of the hierarchical logit model after the introduction of level-2 (group/district level) variable. The group/district level variable is the percentage of women within district who are educated higher levels (12+grades) of schooling. The lowest percentage of the respondents educated higher school levels was recorded in district Shrawasti (2.1 percent) and the highest in the district Kanpur Nagar (27.4 percent). After the introduction of level- 2 variable the odds ratio estimates of the level-1 variables did not change much. However, the level-2 variable is statistically significant, which means percentages of women educated higher school levels within district significantly determine the individual use of contraception in Uttar Pradesh. One percent increase in the proportion of higher educated women within district increases the odds of using contraceptive 1.07 times. The model log likelihood value in as shown helps in rejecting the claim/hypothesis of no significant clustering in the data being present. This also is reflected in the value of ICC in table 4, wherein after accounting for group/district level variable the value of ICC is reduced.

Table 4. Predictors of Contraceptive Use in Uttar Pradesh with Level-2 variable: HLM - Odds Ratio

\begin{tabular}{|c|c|c|c|c|c|c|}
\hline \multirow{2}{*}{$\begin{array}{l}\text { Independent Variable } \\
\text { Level-1 }\end{array}$} & \multirow{2}{*}{ Odds Ratio } & \multirow{2}{*}{ Std. Err. } & \multirow[t]{2}{*}{$\mathrm{z}$} & \multirow{2}{*}{$\mathrm{P}>\mathrm{Z}$} & \multicolumn{2}{|c|}{$[95 \% \mathrm{CI}]$} \\
\hline & & & & & \multirow[b]{2}{*}{1.01} & \multirow[b]{2}{*}{1.02} \\
\hline Current Age (mean centered) & 1.01 & 0.00 & 9.62 & 0.000 & & \\
\hline \multicolumn{7}{|l|}{ Children ever born } \\
\hline$O(R e f)$. & 1.00 & & & & & \\
\hline upto 2 & 10.46 & 0.52 & 47.32 & 0.000 & 9.49 & 11.53 \\
\hline 2 plus & 22.26 & 1.17 & 58.92 & 0.000 & 20.08 & 24.68 \\
\hline \multicolumn{7}{|l|}{ Education } \\
\hline Illiterate (Ref.) & 1.00 & & & & & \\
\hline Upto primary & 1.08 & 0.03 & 2.74 & 0.006 & 1.02 & 1.14 \\
\hline Upto secondary & 1.20 & 0.03 & 7.31 & 0.000 & 1.14 & 1.26 \\
\hline Higher & 1.39 & 0.05 & 8.61 & 0.000 & 1.29 & 1.49 \\
\hline \multicolumn{7}{|l|}{ Place of Residence } \\
\hline Rural & 1.00 & & & & & \\
\hline Urban & 1.08 & 0.03 & 3.22 & 0.001 & 1.03 & 1.14 \\
\hline \multicolumn{7}{|l|}{ Religion } \\
\hline Hindu & 1.00 & & & & & \\
\hline Others & 0.53 & 0.01 & -24.59 & 0.000 & 0.50 & 0.56 \\
\hline \multicolumn{7}{|l|}{ Wealth Index } \\
\hline Poorest (Ref.) & 1.00 & & & & & \\
\hline Poorer & 1.13 & 0.03 & 4.85 & 0.000 & 1.08 & 1.19 \\
\hline Middle & 1.28 & 0.04 & 8.48 & 0.000 & 1.21 & 1.36 \\
\hline Richer & 1.40 & 0.05 & 10.14 & 0.000 & 1.31 & 1.49 \\
\hline Richest & 1.53 & 0.06 & 11.11 & 0.000 & 1.42 & 1.65 \\
\hline \multicolumn{7}{|l|}{ Level-2 } \\
\hline Percentage of women educated $>12$ & 1.07 & 0.02 & 3.51 & 0.000 & 1.03 & 1.11 \\
\hline Constant & 0.02 & 0.01 & -14.99 & 0.000 & 0.01 & 0.03 \\
\hline \multicolumn{7}{|l|}{ Variance component } \\
\hline \multicolumn{7}{|l|}{ Groups (district) } \\
\hline Var. (constant) & 0.55 & 0.09 & & & 0.39 & 0.77 \\
\hline LR test vs. logistic model: chibar2 $(01)=5323.89$ & Prob $>=$ chi & $2=0.000$ & & & & \\
\hline Log likelihood $=-38041.38$ & Prob > chi 2 & $=$ & 0.0000 & & & \\
\hline
\end{tabular}

\section{Conclusion}

The findings from the study reinforce the importance of female education in Uttar Pradesh which increases the odds of use of contraception at individual level. The within district individual variance being large compared to between district variance is indicative of the importance of female education within districts. The increase in higher educated females within district increases the odds of use of contraception at Individual level substantially. The finding has huge programmatic implications. The program managers must focus of districts where percentages of female educated higher $(12+$ grades $)$ school levels are low. Financial incentives within district with low percentages of higher educated women 
may be a good strategy, as it may increase individual decision making in matters relating to contraception and limiting family size.

\section{Policy Recommendation}

Government of Uttar Pradesh may focus on districts with low proportion of women educated higher school levels and promote females education in these set of districts.

\section{References}

Goldstein, H. (1995). Hierarchichal data modeling in the social science. Journal of Educational and Behavioral Statistics, 20(2), 201-204. https://doi.org/10.3102/10769986020002201

Hox, J. J. (2010). Multilevel Analysis Techniques and Applications. New York: Taylor and Francis Group. https://doi.org/10.4324/9780203852279

IIPS, I. (2017). National Family Health Survey (NFHS-4), 2015-16. International Institute for Population Sciences (IIPS), Mumbai, India.

International Institute for Population Sciences (IIPS) and Macro International (2007). National Family Health Survey (NFHS-3), 2005-06: India: Volume 1. Mumbai IIPS.

Rabe-Hesketh, S., Skrondal, A., \& Pickles, A. (2004). GLLAMM manual. UC Berkeley division of biostatistics working paper series. University of California, Berkeley.

Sharma, S. K., Ghimire, D. R., \& Pratap, N. (2011). Ethnic differentials of the impact of Family Planning Program on contraceptive use in Nepal. Demographic Research, 25, 837-868. https://doi.org/10.4054/DemRes.2011.25.27

Srinivasan, K. (2001). The Population Issue in the New Millennium: The Legacy and the Challenges. In Eds. K. Srinivasan and Michael Vlassoff, IASP conference volume Population Development Nexus in India: Challenges for the New Millennium, Tata McGraw-Hill Publishing Co. Ltd., New Delhi.

Stephenson, R., Baschieri, A., Clements, S., Hennink, M., \& Madise, N. (2007). Contextual influences on modern contraceptive use in sub-Saharan Africa. American Journal of Public Health, 97(7), 1233-1240. https://doi.org/10.2105/AJPH.2005.071522

Stephenson, R., Beke, A., \& Tshibangu, D. (2008). Community and health facility influences on contraceptive method choice in the Eastern Cape, South Africa. International Family Planning Perspectives, 34(2), 62-70. https://doi.org/10.1363/3406208

\section{Copyrights}

Copyright for this article is retained by the author(s), with first publication rights granted to the journal.

This is an open-access article distributed under the terms and conditions of the Creative Commons Attribution license (http://creativecommons.org/licenses/by/4.0/). 